\title{
A PROSPECTIVE STUDY OF LOW T3 SYNDROME IN CHRONIC HEART FAILURE
}

Arun Kumar N1, S. M. Manjunatha², Yatish S. K³, Mohan Kumar4, Ravi Shankar A. G5, Ramesh S. S6, M. M. Basavaraju ${ }^{7}$, Shekar M. A ${ }^{8}$

\section{HOW TO CITE THIS ARTICLE:}

Arun Kumar N, S. M. Manjunatha, Yatish S. K, Mohan Kumar, Ravi Shankar A. G, Ramesh S. S, M. M. Basavaraju, Shekar M. A. "A Prospective Study of Low T3 Syndrome in Chronic Heart Failure". Journal of Evolution of Medical and Dental Sciences 2014; Vol. 3, Issue 08, February 24; Page: 1958-1968,

DOI: $10.14260 /$ jemds/2014/2087

ABSTRACT: BACKGROUND: Thyroid abnormalities are common in chronic heart failure. Severity of heart failure rises by several fold in patients with thyroid dysfunction. OBJECTIVES: The purpose of this cross sectional comparative study is to determine the correlation between low T3 syndrome and chronic heart failure \& predicting the severity of chronic heart failure. METHODS: In this descriptive, cross sectional study, all patients who presented to the Department of medicine with chronic heart failure during this study period of 12 months from January 2010-December 2011 in K.R.Hospital, Mysore were included. Patients were grouped into Low T3 chronic heart failure (10); hypothyroid chronic heart failure (29) and chronic heart failure (11) were included. RESULTS: Mean age of low T3

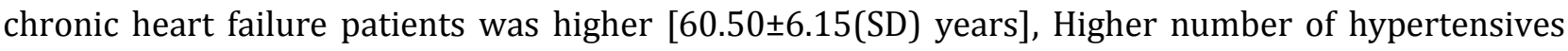
were seen in low T3 chronic heart rate patients, Cardiomyopathy was most common etiology for chronic heart failure patients (42\%) and was common in the age group of 55-60 years (38\%) in present study, idiopathic etiology was common in the age group of 60-65 years (63\%), hypertensive heart disease as etiology was common with age group of 45-50 years (42.8\%), IHD etiology was common with age group of 55-60 years (36.3\%). Idiopathic etiology was common etiology with low T3 chronic heart rate patients (60\%) and all patients was seen in the age group of 55-65 years. Mean pulse rate was higher in low T3 chronic heart failure group [104 \pm 6.9 (SD) beats $/ \mathrm{min}]$. Systolic blood pressure was high in low T3 chronic heart rate group [131 \pm 20.8 (SD) $\mathrm{mm}$ of $\mathrm{Hg}$; diastolic blood

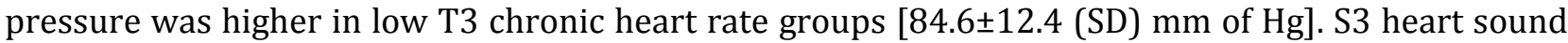
was present in more number of patients with low T3 chronic heart rate (60\%), Systolic dysfunction on 2D Echo was more in low T3 chronic heart failure group (20\%), Diastolic dysfunction on 2D Echo was more in low T3 chronic heart failure group (30\%), Global hypokinesia was seen in more number of patients with low T3 chronic heart failure (30\%).Segmental hypokinesia was seen in more number of patients with low T3 chronic heart failure (3\%). Mean ejection fraction was seen in more number of patients with low T3 chronic heart failure [36.78 \pm 5.08 (SD) \%].Mean ejection fraction was lower in low T3 chronic heart failure [34.8 \pm 3.293 (SD) \%].The high pulmonary artery systolic pressure was seen in more number of patients in low T3 chronic heart failure (70\%). CONCLUSION: There is significant percentage of chronic heart failure patients having low T3 alone as biochemical parameter. It is important to recognize patients with chronic heart failure as it is associated with increased severity of heart failure.

KEYWORDS: chronic heart failure, low T3 syndrome, systolic blood pressure, diastolic blood pressure and PR interval. 
INTRODUCTION: Clinical and experimental evidence have shown that T3 plays a major role in modulating heart rate and cardiac contractility as well as arterial peripheral resistance. T3 actions are carried out by binding with specific nuclear receptors that regulate responsive genes encoding for structural and functional cardiac proteins; direct, extra-nuclear, non-transcriptional effects have also been described ${ }^{1,2}$.

The cardiovascular system is one of the most important targets on which thyroid hormones act. More than $80 \%$ of the biologically active hormone tri-iodothyronine (T3) derives from peripheral conversion of pro-hormone thyroxine (T4) secreted by the thyroid gland. ${ }^{3}$

A typical pattern of altered thyroid hormone metabolism characterized by low T3 circulating levels has been described in patients with acute myocardial infarction ${ }^{4,5}$ and heart failure and in adults and children after cardiopulmonary bypass. The principal pathophysiological mechanism underlying low circulating T3 is the reduced enzyme activity of $5^{\prime}$ monodeiodinase responsible for converting T4 into T3 in peripheral tissues. ${ }^{6-10}$

This low-T3 syndrome has commonly been interpreted by the medical community as a euthyroid sick syndrome, an adaptive compensatory and thus beneficial response that decreases energy consumption in diseased states. This interpretation, however, has recently been questioned. Although clinical data documented the benefit gained from treating patients with synthetic thyroid hormones. ${ }^{11-19}$

A new study in rats is giving researchers hope that more aggressive treatment of hypothyroidism and borderline hypothyroidism will result in a reduction of chronic heart failure in human beings. ${ }^{20}$

Low thyroid function alone induced in rats eventually can cause heart failure. "It was also discovered that low thyroid function severely impaired cardiac blood flow due to a dramatic loss of the hearts small blood vessels (arterioles). Within six weeks after inducing low thyroid function in rats, half of the heart's small arterioles were gone." hypothyroidism led to severe, progressive contractile dysfunction, chamber enlargement, and ventricular wall thinning despite a reduction in cardiac mass. Hypothyroidism induced in the rats also resulted in impaired myocardial blood flow due to a dramatic loss of arterioles. As a result, it identified two new mechanisms by which low thyroid function may lead to heart failure. ${ }^{20}$

The results suggested that individuals with borderline hypothyroidism may also have similar cardiac changes. Clearly more research is needed to determine if these detrimental cardiac changes occur in humans and if treatment of heart patients with borderline hypothyroidism will lead to improved outcomes. ${ }^{20}$

\section{OBJECTIVES OF THE STUDY:}

- To determine the patients of chronic heart failure by clinical and investigational methods.

- To screen the chronic heart failure patients by subjecting them to thyroid profile.

- To find an association between Low T3 syndrome and chronic heart failure.

- To determine the severity of cardiac failure in low T3 syndrome patients.

\section{METHODOLOGY:}

Study Design: Cross sectional comparative study.

Sample Size: Study group comprised of 50 cases over a span of 12 months from January 2010December 2011 in K.R.Hospital, Mysore. 
Method of Collection of Data: The data for the purpose of this cross sectional comparative study was collected in a predesigned and pretested proforma which include various socioeconomic parameters like age, sex, occupation, religion, etc. About 50 cases were selected on the basis of the simple Random Sampling Method.

The statistically data was analyzed ANOVA, factor analysis and Chi-square test

Inclusion Criteria: Patients with chronic heart failure. Exclusion Criteria:

1. Included clinical evidence of sepsis or cachexia or

2. Concomitant presence of any predominant severe systemic disease including severe anemia $\mathrm{Hb} \%<5 \mathrm{~g} \%$.

3. Other major surgical procedures performed before or within 6 months after the time of thyroid sampling.

Routine investigations were done to assess thyroid function and to clinically diagnose chronic heart failure. Investigations are as follows:

The thyroid function profile: After rapid centrifugation of a venous sample,

Total T3 (TT3),

fT3, Total T4 (TT4),

fT4 and TSH will be measured.

Questionnaires were given. Physical examination, radiographic examination and echocardiography for diagnosing \& characterizing chronic heart failure were done.

All these methods, however, have major limitations when used independently.

Scoring systems that combine several of the measures discussed below have been developed for use in population-based studies for chronic heart failure.

RESULTS: In this study titled "Low T3 in chronic heart failure- a cross sectional comparative study" comprising of 50 chronic heart failure patients admitted to KR hospital, Mysore who are studied under three groups namely Hypothyroid, Low T3 \& CHF only.

Table 1 shows among 50 chronic heart failure patients 29 patients (58\%) are hypothyroid, 10 patients (20\%) have low T3 alone. Mean age for Low T3 chronic heart failure patients was $60.50 \pm$ 6.15 (SD) years which was higher when compared to mean age 59.91ะ5.99 (SD) years for CHF only patients \& $54.9 \pm 5.49$ (SD) years for hypo thyroid chronic heart failure patients in the present study which was statistically significant $(\mathrm{p}<0.01)$. The mean age of chronic heart failure patients in the present study was $58.43 \pm 5.87$ (SD) years.

Mean duration of symptoms in the hypothyroid chronic heart failure patient was $2.80 \pm 2.24$ (SD) months, mean duration of symptoms in the Low T3 chronic heart failure patients was $3.85 \pm 1.63$ (SD) months, mean duration of symptoms in chronic heart failure only patient was $5.64 \pm 6.63$ (SD) months. The duration of symptoms was higher in chronic heart failure only patients when compared to other two groups in the present study which was statistically significant $(\mathrm{p}<0.01)$.

Majority of chronic heart failure patients are in the age group of 55-60yrs (32\%) followed by 60-65 yrs. (22\%) \& 50-55 yrs. (18\%) in the present study. Majority of patients $(90 \%)$ with low T3 chronic heart failure are within the age group 55-70yrs. 
The male: female ratio of patients in the present study was 3.56:2. The male: female ratio of patients' with hypothyroid chronic heart failure in the present study was 4.4: 2 . The male: female ratio of patients with chronic heart failure only in the present study was 2.4: 2 . The male: female ratio in patients with Low T3 chronic heart failure was 3:2. This shows that male domination is seen in patients with low T3 chronic heart failure, hypothyroid chronic heart failure \& chronic heart failure only groups.

Table 2 shows that fatigue and generalized weakness, dyspnea on exertion, swelling of feet, hoarse voice, hair loss, cold intolerance and decreased libido are common symptoms of patient with low T3 chronic heart failure. Orthopnea, PND and puffiness of eyes were not common symptom in this group.

Paresthesia is seen in $18.18 \%$ of chronic heart failure only patients, when compared to none in Low T3 and Hypothyroid chronic heart failure patients. Impaired hearing was seen in $9.09 \%$ of chronic heart failure patients, when compared to $3.45 \%$ of hypothyroid chronic heart failure patients \& none of low T3 Chronic Heart Failure patients. Decreased Libido was seen in $20 \%$ of low T3 chronic heart failure patients, when compared to $3.45 \%$ of hypothyroid chronic heart failure \& none of chronic heart failure only patients.

Weight gain with poor appetite was seen in $18.18 \%$ chronic heart failure only patients, when compared to $17.24 \%$ of hypothyroid chronic heart failure patients, and $1 \%$ of low T3 chronic heart failure patients. Hoarse voice was seen in $36.36 \%$ of chronic heart failure only patients, when compared to $30 \%$ of low T3 chronic heart failure patients' and $17.24 \%$ of hypothyroid chronic heart failure patients.

Alcoholics contributed to $78 \%$ of patients with chronic heart failure in the present study of which $20.51 \%$ were female.

Table 3 shows total number of IHD in hypothyroid chronic heart failure patients was higher (44.82\%) when compared to $40 \%$ in low T3 chronic heart failure patients \& $36.36 \%$ in CHF only group in the present study which was not statistically significant $(\mathrm{p}<0.88)$. IHD contributed to $42 \%$ of patients with chronic heart failure.

Table 4 shows that cardiomyopathy formed most common etiology (42\%) followed by IHD \& idiopathic (22\%), HHD (14\%) in patients with chronic heart failure, the cardiomyopathy was more in the age group of 55-60 yrs. (38\%). Idiopathic etiology was more common in the age group of 60 65yrs (63.7\%). Hypertensive heart disease as an etiology was more common in the age group of 45$50 y$ rs (42.8\%). IHD as an etiology was more common in the age group between 55-60yrs (36.3\%).

Table 5 shows that cardiomyopathy formed most common etiology (48.2\%) followed by IHD (27.58\%), HHD (17.24\%) \& idiopathic (6.8\%) in patients with hypothyroid chronic heart failure in present study. Thus cardiomyopathy was more in the age group of 55-60 yrs. (42.8\%). Idiopathic etiology was more equally common in the age group of 50-55yrs (50\%) \& 60-65yrs (50\%). Hypertensive heart disease as an etiology was more common in the age group of 45-50yrs (40\%). IHD as an etiology was more common in the age group between 50-60yrs (70\%).

Table 6 shows that idiopathic etiology formed most common etiology $(60 \%)$ followed by cardiomyopathy (20\%), IHD (10\%) \& HHD (10\%) in patients with low T3 chronic heart failure in present study. IHD and cardiomyopathy was seen only in the age group of 65-70yrs. Idiopathic etiology was equally seen in 55-60yrs (50\%) and 60-65yrs (50\%) and hypertensive heart disease as etiology was seen only in 50-55yrs (100\%) in the present study. 
Table 7 Cardiomyopathy formed most common etiology for CHF only patients (45.45\%) followed by Idiopathic (27.27\%), IHD (18.18\%) \& HHD $(9.09 \%)$ in patients with chronic heart failure only in present study. Cardiomyopathy was seen in more number of patients at 55-60yrs (40\%). Idiopathic etiology was seen only in 60-65yrs. Hypertensive heart disease etiology was seen only in age group of 45-50yrs.IHD etiology was seen equally in age group of 55-60yrs (50\%) and 65-70yrs (50\%) age group.

Mean pulse rate of patients with chronic heart failure was 95.8 6.5 (SD) beats/minute in the present study. Table.16 shows the mean pulse rate was higher in Low T3 chronic heart failure group [104 6.9 (SD)/min] when compared to hypothyroid chronic heart failure group which was $94 \pm$ 4.3(SD) min \& mean pulse rate in CHF only group was $90.9 \pm 4.2$ (SD) $/ \mathrm{min}$ in present study which is statistically significant $(\mathrm{P}<0.000)$.

S3 was present in $60 \%$ of patients with low T3 chronic heart failure patients when compared to $54.5 \%$ of CHF only patients \& $10.3 \%$ of hypothyroid chronic heart failure patients in the present study. Which was statistically significant $(\mathrm{p}<0.002)$.

Estimated creatinine clearance in Low T3 chronic heart failure group is $25.8 \pm 8.5$ (SD) $\mathrm{ml} / \mathrm{min}$ which was lower when compared to hypothyroid chronic heart failure group which was 51.4 \pm 18.6 (SD) $\mathrm{ml} / \mathrm{min} \& \mathrm{CHF}$ only group $52.9 \pm 20.6$ (SD) $\mathrm{ml} / \mathrm{min}$ and in present study which was statistically significant $(\mathrm{P}<0.000)$.

Renal dysfunction was common in Low T3 chronic heart failure group compared to the other two groups, with high mean blood urea [74.2 \pm 18.9 (SD) $\mathrm{mg} / \mathrm{dl}]$ high mean serum creatinine $[2.5 \pm 0.3$ (SD) $\mathrm{mg} / \mathrm{dl}$ ], higher mean serum potassium [3.9 \pm 0.2 (SD) $\mathrm{mEq} / \mathrm{l}]$ and lower estimated creatinine clearance $[25.8 \pm 8.5(\mathrm{SD}) \mathrm{ml} / \mathrm{min}]$ as estimated by MDRD formula.

The mean PR Interval was more prolonged in Low T3 chronic heart failure patients [0.21 0.023 (SD) sec] when compared $0.16 \pm 0.027$ (SD) sec in hypothyroid chronic heart failure group \& $0.15 \pm 0.022$ (SD) sec in CHF Only group in present study which was statistically significant $(\mathrm{P}<0.000)$.

Patients with Low T3 chronic heart failure had a low mean EF of [34.8 3.293 (SD) \%] when compared 36.66 5.563 (SD) \% in hypothyroid chronic heart failure group \& 38.91 \pm 4.592 (SD) \% in CHF only group in present study, which was statistically not significant $(\mathrm{p}<0.178)$. The mean EF of patients with chronic heart failure in present study was $36.78 \pm 5.08$ (SD) $\%$.

Majority of patients with hypothyroid chronic heart failure were within the age group of 55$60 y$ rs $(34.48 \%)$ and patients with hypothyroid chronic heart failure had low mean EF 36.6 5.5 (SD) $\%$ with age group of 60-65yrs in the present study.

There was equal distribution of patients with low T3 chronic heart failure in age group 5560yrs (30\%), 60-65yrs (30\%) \& 65-70yrs (30\%), patients with low T3 chronic heart failure had low mean EF $32 \pm 2.3$ (SD) \% with age group of 50-55yrs in the present study.

Majority of patients with chronic heart failure only were within age group of 60-65yrs (36.36\%). The patients with CHF only had low mean EF $34 \pm 3$ (SD) \% with age group of 65-70yrs in the present study.

The mean EF of patient with low T3 was lower [34.8 3.2 (SD) \%] when compared to 36.66 \pm 5.5 (SD) \% in hypo thyroid chronic heart failure and 38.9 5 (SD) \% in CHF alone in the present study which was statistically not significant $(\mathrm{p}<0.178)$. 


\section{ORIGINAL ARTICLE}

DISCUSSION: Low thyroid hormone concentrations, in particular low serum T3 concentrations, are a common finding in patients with non-thyroidal illnesses, including cardiac disorders. Its pathophysiological role is not well understood, although the common belief is in favor of an adaptive mechanism to preserve energy. Nonetheless, based on the knowledge of the fundamental actions of T3 on both the heart and vessels, a direct relationship between low circulating levels of T3 and adverse prognosis of cardiac patients has represented an attractive hypothesis in the last few years. In this respect, it has been postulated that the low T3 state may produce a hypothyroid-like syndrome that contributes to the worsening or exacerbation of the intrinsic cardiac disease.

The low T3 circulatory levels were found in $20 \%$ of patients with chronic heart failure in the present study. Mean age for Low T3 chronic heart failure patients was $60.50 \pm 6.15$ (SD) years which was higher when compared to mean age of chronic heart failure only patients which was $59.91 \pm 5.99$ (SD) years and 54.9 \pm 5.49 (SD) years for hypo thyroid chronic heart failure patients in the present study which shows that low T3 chronic heart failure occurs in more elderly patients with chronic heart failure. The mean age of chronic heart failure patients in the present study was $58.43 \pm 5.87$ (SD) years which was comparable to Joao Paulo Solano, George Marzouka and ACC 2011.2,4

Mean duration of symptoms in the hypothyroid chronic heart failure patients was shorter i.e. $2.80 \pm 2.24(\mathrm{SD})$ months. The mean duration of symptoms was longer for chronic heart failure only patients; $5.64 \pm 6.63(\mathrm{SD})$ months. The mean duration of symptoms for low T3 chronic heart failure was in between i.e. is $3.85 \pm 1.63$ (SD) months.

Male: female ratio of patients with hypothyroid chronic heart failure in the present study was 4.4: 2. The male: female ratio in patients with Low T3 chronic heart failure was 3:2. The male: female ratio of patients with chronic heart failure only in the present study was 2.4: 2 . This shows that hypothyroid chronic heart failure had more male predominance when compared the other two groups, which was compared to George Marzouka and ACC 2011. The male: female ratio of patients in the present study was 3.56:2.

Fatigue and generalized weakness was present with $72 \%$ of patients with chronic heart failure in the present study which was comparable to Veronique L.Roger. Swelling of feet was present in $74 \%$ of patients with chronic heart failure in the present study which was comparable to Deborah D.Ascheim. 5,6

Dyspnea on exertion was present in $52 \%$ of patients with chronic heart failure in present study, which was comparable to Veronique L. Roger. Puffiness of face was present in $34 \%$ of patients with chronic heart failure in the present study. Orthopnea was present in $26 \%$ of patients with chronic heart failure in the present study, which was comparable to Deborah D. Ascheim. PND was present in $24 \%$ of patients with chronic heart failure in present study. Hoarse voice was present in $24 \%$ of chronic heart failure patients in present study. Hair loss was present in $22 \%$ of chronic heart failure patients in present study.

Fatigue and generalized weakness, dyspnea on exertion, swelling of feet, cold intolerance, hair loss, hoarse voice and decreased libido are common symptoms of low T3 chronic heart failure. Orthopnea was seen in less number of patients with low T3 chronic heart failure when compared to other two groups.

None of low T3 chronic heart failure patients had PND, paresthesia, impaired hearing, and puffiness of eyes. This shows that there was worsening of heart failure in patients with low T3 
chronic heart failure in the form of dyspnea on exertion, swelling of feet, fatigue and generalized weakness in the present study.

This also shows that low T3 chronic heart failure patients had symptoms of hypothyroid like syndrome in the form of cold intolerance, hair loss and hoarse voice in the present study. This also shows that symptoms and signs of chronic heart failure were more severe in patients with low T3 chronic heart failure.

Alcoholics contributed to $78 \%$ of patients with chronic heart failure in the present study and incidence of alcoholism was higher in patients with low T3 chronic heart failure when compared to the other two groups in present study (80\%). Females contributed to $20.51 \%$ of alcoholic patients in the present study. This shows that low T3 chronic heart failure patient was common in alcoholic patients.

Patients with IHD contributed to $22 \%$ of patients with chronic heart failure and higher number of patients with IHD was seen in hypothyroid chronic heart failure group when compared to the other two groups (44.82\%). This shows that IHD did not contribute higher incidence of low T3 chronic heart failure.

Cardiomyopathy was most common etiology for chronic heart failure (42\%) and was comparable to ACC 2011.4,5

Table.33 cardiomyopathy was common in age group of 55-60 years (38\%) in the present study. Idiopathic etiology was more common with age group of 60-65 years (63\%). Hypertensive etiology was common with age group of 45-50 years (42.8\%). IHD etiology was common in the age group of 55-60 years (36.3\%). Cardiomyopathy was common etiology in patients with hypothyroid chronic heart failure (48.2\%) in the present study, $42 \%$ of which were in the age group of 55-60 years. Idiopathic etiology was common etiology in patients with low T3 chronic heart failure (60\%) and all patients were seen in the age group of 55-65 years. Cardiomyopathy formed common etiology in patients with chronic heart failure only group (45.45\%) and $40 \%$ of patients was seen in the age group of 55-60 years.

Skin changes on general examination were seen in $60 \%$ of patients with low T3 chronic heart failure.

Third heart sound was present in more number of patients with low T3 chronic heart failure (60\%) when compared to other two groups. This showed that low T3 chronic heart failure had severe degree of heart failure. Third heart sound was present in $30 \%$ of patients in chronic heart failure in present study which was comparable to ACC 2011.4, 5,8,9

Table.40 shows mean ejection fraction was lower in patient with low T3 chronic heart failure [34.8 \pm 3.293 (SD) \%] when compared to other two groups.

This showed that the severity of heart failure was higher in patients with low T3 chronic heart failure and incidence of IHD in the form of global hypokinesia and segmental hypokinesia was lesser in patients with low T3 chronic heart failure.

The high pulmonary artery systolic pressure was seen in more number $(70 \%)$ of patients with low T3 chronic heart failure group when compared to other two groups; this shows increase in severity of right heart failure in patients with low T3 chronic heart failure in the present study.

CONCLUSION: There is significant percentage of chronic heart failure patients having low T3 alone as biochemical parameter. It is important to recognize this condition in patients with chronic heart failure as it is associated with increased severity of heart failure, increased in evidence of renal failure 
which may need additional support of thyroid hormone administration to have a better outcome in patients with chronic heart failure.

\begin{tabular}{|c|c|c|}
\hline Group & Number of patients & Percentage (\%) \\
\hline Hypothyroid & 29 & 58 \\
\hline Low T3 & 10 & 20 \\
\hline CHF Only & 11 & 22 \\
\hline Total & 50 & 100 \\
Table - 1: Prevalence of hypothyroidism, \\
low T3 and CHF only in present study \\
\hline
\end{tabular}

\begin{tabular}{|l|c|c|c|c|}
\hline \multicolumn{1}{|c|}{ Symptoms } & $\begin{array}{c}\text { Hypothyroid } \\
\text { (n=29) }\end{array}$ & $\begin{array}{c}\text { Low T3 } \\
(\mathbf{n = 1 0 )}\end{array}$ & $\begin{array}{c}\text { CHF Only } \\
(\mathbf{n = 1 1})\end{array}$ & $\begin{array}{c}\text { Total } \\
\text { (n=50) }\end{array}$ \\
\cline { 2 - 5 } & Number (\%) & Number (\%) & Number (\%) & Number (\%) \\
\hline Fatigue, generalized weakness & $19(65.52 \%)$ & $9(90 \%)$ & $8(72.73 \%)$ & $36(72 \%)$ \\
\hline Dry skin & $1(3.45 \%)$ & $0(0 \%)$ & $0(0 \%)$ & $1(2 \%)$ \\
\hline Cold intolerance & $1(3.45 \%)$ & $3(30 \%)$ & $2(18.18 \%)$ & $6(12 \%)$ \\
\hline Hair Loss & $6(20.69 \%)$ & $4(40 \%)$ & $1(9.09 \%)$ & $11(22 \%)$ \\
\hline Dyspnea on exertion & $13(44.83 \%)$ & $10(100 \%)$ & $3(27.27 \%)$ & $26(52 \%)$ \\
\hline Weight gain with poor appetite & $5(17.24 \%)$ & $1(10 \%)$ & $2(18.18 \%)$ & $8(16 \%)$ \\
\hline PND & $10(34.48 \%)$ & $0(0 \%)$ & $2(18.18 \%)$ & $12(24 \%)$ \\
\hline Orthopnea & $6(20.69 \%)$ & $1(10 \%)$ & $6(54.55 \%)$ & $13(26 \%)$ \\
\hline Hoarse voice & $5(17.24 \%)$ & $3(30 \%)$ & $4(36.36 \%)$ & $12(24 \%)$ \\
\hline Paresthesias & $0(0 \%)$ & $0(0 \%)$ & $2(18.18 \%)$ & $2(4 \%)$ \\
\hline Impaired hearing & $1(3.45 \%)$ & $0(0 \%)$ & $1(9.09 \%)$ & $2(4 \%)$ \\
\hline Swelling of feet & $20(68.97 \%)$ & $9(90 \%)$ & $8(72.73 \%)$ & $37(74 \%)$ \\
\hline Puffiness of face & $11(37.93 \%)$ & $2(20 \%)$ & $4(36.36 \%)$ & $17(34 \%)$ \\
Puffiness of eyes & $2(6.90 \%)$ & $0(0 \%)$ & $1(9.09 \%)$ & $3(6 \%)$ \\
\hline Decreased Libido & $1(3.45 \%)$ & $2(20 \%)$ & $0(0 \%)$ & $3(6 \%)$ \\
\hline
\end{tabular}

Table - 2: Analysis of symptoms of chronic heart failure in the present study

\begin{tabular}{|c|c|c|}
\hline Groups & Non-IHD & IHD \\
\hline Hypothyroid $(n=29)$ & $16(55.17 \%)$ & $13(44.82 \%)$ \\
\hline Low T3 $(n=10)$ & $6(60 \%)$ & $4(40 \%)$ \\
\hline $\mathrm{CHF}(\mathrm{n}=11)$ & $7(63.63 \%)$ & $4(36.36 \%)$ \\
\hline Total & 29 & 21 \\
\hline
\end{tabular}

$(\mathrm{p}<0.88)$ 
ORIGINAL ARTICLE

\begin{tabular}{|c|c|c|c|c|c|}
\hline Age group & IHD & HHD & RHD & Cardiomyopathy & Idiopathic \\
\hline In years & No $(\%)$ & No $(\%)$ & No (\%) & No $(\%)$ & No (\%) \\
\hline $45-50$ & $2(18.2 \%)$ & $3(42.8 \%)$ & - & $2(9.5 \%)$ & - \\
\hline $50-55$ & $3(27.3 \%)$ & $2(28.5 \%)$ & - & $3(14.35 \%)$ & $1(9 \%)$ \\
\hline $55-60$ & $4(36.3 \%)$ & $1(14.35 \%)$ & - & $8(38 \%)$ & $3(27.3 \%)$ \\
\hline $60-65$ & - & $1(14.35 \%)$ & - & $3(14.35 \%)$ & $7(63.7 \%)$ \\
\hline $65-70$ & $2(18.2 \%)$ & -- & - & $5(23.8 \%)$ & - \\
\hline Total & $11(22 \%)$ & $7(14 \%)$ & - & $21(42 \%)$ & $11(22 \%)$ \\
\hline
\end{tabular}

\begin{tabular}{|c|c|c|c|c|c|}
\hline \multirow{2}{*}{$\begin{array}{c}\text { Age group } \\
\text { In years }\end{array}$} & IHD & HHD & RHD & Cardiomyopathy & Idiopathic \\
\cline { 2 - 7 } & No (\%) & No (\%) & No (\%) & No (\%) & No (\%) \\
\hline $45-50$ & $2(25 \%)$ & $2(40 \%)$ & - & $2(14.2 \%)$ & - \\
\hline $50-55$ & $3(37.5 \%)$ & $1(20 \%)$ & - & $2(14.2 \%)$ & $1(50 \%)$ \\
\hline $55-60$ & $3(37.5 \%)$ & $1(20 \%)$ & - & $6(42.8 \%)$ & - \\
\hline $60-65$ & - & $1(20 \%)$ & - & $2(14.2 \%)$ & $1(50 \%)$ \\
\hline $65-70$ & - & - & - & $2(14.2 \%)$ & - \\
\hline Total & $8(27.58 \%)$ & $5(17.24 \%)$ & - & $14(48.2 \%)$ & $2(6.8 \%)$ \\
\hline \multicolumn{7}{|c|}{$\begin{array}{r}\text { Table - 5: Correlation between age and etiology } \\
\text { in hypothyroid (n=29) group in present study }\end{array}$} \\
\hline
\end{tabular}

\begin{tabular}{|c|c|c|c|c|c|}
\hline $\begin{array}{c}\text { Age group } \\
\text { In years }\end{array}$ & IHD & HHD & RHD & Cardiomyopathy & Idiopathic \\
\cline { 2 - 6 } & No (\%) & No (\%) & No (\%) & No (\%) & No (\%) \\
\hline $45-50$ & - & - & - & - & - \\
\hline $50-55$ & - & $1(100 \%)$ & - & - & - \\
\hline $55-60$ & - & - & - & - & $3(50 \%)$ \\
\hline $60-65$ & - & - & - & - & $3(50 \%)$ \\
\hline $65-70$ & $1(100 \%)$ & - & - & $2(100 \%)$ & - \\
\hline Total & $1(10 \%)$ & $1(10 \%)$ & - & $2(20 \%)$ & $6(60 \%)$ \\
\hline \multicolumn{7}{|c|}{$\begin{array}{r}\text { Table - 6: Correlation between age and etiology } \\
\text { in low T3 (n=10) group in present study }\end{array}$} \\
\hline
\end{tabular}

\begin{tabular}{|c|c|c|c|c|c|}
\hline $\begin{array}{c}\text { Age group } \\
\text { In years }\end{array}$ & IHD & HHD & RHD & Cardiomyopathy & Idiopathic \\
\cline { 2 - 6 } & No (\%) & No (\%) & No (\%) & No (\%) & No (\%) \\
\hline $45-50$ & - & $1(100)$ & - & - & - \\
\hline $50-55$ & - & - & - & $1(20 \%)$ & - \\
\hline $55-60$ & $1(50 \%)$ & - & - & $2(40 \%)$ & - \\
\hline $60-65$ & - & - & - & $1(20 \%)$ & $3(100 \%)$ \\
\hline $65-70$ & $1(50 \%)$ & - & - & $1(20 \%)$ & - \\
\hline Total & $2(18.18 \%)$ & $1(9.09 \%)$ & - & $5(45.45 \%)$ & $3(27.27 \%)$ \\
\hline \multicolumn{7}{|c|}{$\begin{array}{r}\text { Table - 7: Correlation between age and etiology } \\
\text { in CHF only (n=11) group in present study }\end{array}$} \\
\hline
\end{tabular}


ORIGINAL ARTICLE

\begin{tabular}{|c|c|c|c|c|c|}
\hline PARAMETER & ACC 2011 & Cowie & NHANES (I) & Gheorgiade & Present Study \\
\hline HHD & $78.2 \%$ & - & $10 \%$ & - & $14 \%$ \\
\hline DM & $35.8 \%$ & - & $32 \%$ & - & $42 \%$ \\
\hline IHD & $35.2 \%$ & $32 \%$ & $62 \%$ & $68 \%$ & $22 \%$ \\
\hline DCM & $52 \%$ & - & - & - & $42 \%$ \\
\hline
\end{tabular}

Table - 8: Comparative study of etiology in heart failure

\begin{tabular}{|c|c|c|c|c|c|}
\hline \multirow{2}{*}{ EF in \% } & $\begin{array}{c}\text { Deborah } \\
\text { D.ascheim } \\
\mathbf{2 0 0 2}\end{array}$ & $\begin{array}{c}\text { Joao Paulo } \\
\text { Solano, } \\
\mathbf{2 0 0 6}\end{array}$ & $\begin{array}{c}\text { George } \\
\text { Marzouka } \\
\mathbf{2 0 0 4}\end{array}$ & ACC 2011 & $\begin{array}{c}\text { Present } \\
\text { study }\end{array}$ \\
\cline { 2 - 6 } & $35 \pm 6.6 \%$ & $42 \pm 6$ & $24 \pm 9 \%$ & $24 \pm 9$ & $36 \pm 4.3$ \\
\hline \multicolumn{3}{|r}{ Table - 9: Comparative study 2D-Echo changes in heart failure }
\end{tabular}

\section{REFERENCES:}

1. Polikar R, Burger AG, Scherrer U, et al. The thyroid and the heart. Circulation. 1993; 87: 14351441.

2. Klein I, Ojamaa K. Mechanism of disease: thyroid hormone and the cardiovascular system. N Engl J Med. 2001; 344: 501-509.

3. Pilo A, Iervasi G, Vitek F, et al. Thyroidal and peripheral production of 3, 5, 3'-triiodothyronine in humans by multicompartmental analysis. Am J Physiol. 1990; 258: E715-E726.

4. Franklyn JA, Gammage MD, Ramsden DB, et al. Thyroid status in patients after acute myocardial infarction. Clin Sci (Colch). 1984; 67: 585-590.

5. Wiersinga WM, Lie KI, Toubler JL. Thyroid hormones in acute myocardial infarction. Clin Endocrinol. 1981; 14: 367-374.

6. Hamilton MA, Stevenson LW, Luu M, et al. Altered thyroid hormone metabolism in advanced heart failure. J Am Coll Cardiol. 1990; 16: 91-95.

7. Klemperer JD, Klein I, Gomez M, et al. Thyroid hormone treatment after coronary artery bypass surgery. N Engl J Med. 1995; 333: 1522-1527.

8. Murzi B, Iervasi G, Masini S, et al. Thyroid hormones homeostasis in pediatric patients during and after cardiopulmonary by-pass. Ann Thorac Surg. 1995; 59: 481-485.

9. Holland FW, Brown PS, Weintraub BD, et al. Cardiopulmonary bypass and thyroid function: a "euthyroid sick syndrome." Ann Thorac Surg. 1991; 52: 46-50.

10. Utiger RD. Altered thyroid function in nonthyroidal illness and surgery: to treat or not to treat? N Engl J Med. 1995; 333: 1562-1563.

11. Chopra IJ. Euthyroid sick syndrome: is it a misnomer? J Clin Endocrin Metab. 1997; 82: 329334.

12. De Groot LJ. Dangerous dogmas in medicine: the nonthyroidal illness syndrome. J Clin Endocrin Metab. 1999; 84: 151-164.

13. Moruzzi P, Doria E, Agostoni PG. Medium-term effectiveness of L-thyroxine treatment in idiopathic dilated cardiomyopathy. Am J Med. 1996; 101: 461-467. 
14. Mullis-Jansson SL, Argenziano M, Corwin S, et al. A randomized double-blind study of the effect of triiodothyronine on cardiac function and morbidity after coronary bypass surgery. J Thorac Cardiovasc Surg. 1999; 117: 1128-1135.

15. Bettendorf M, Schmidt KG, Grulich-Henn J, et al. Tri-iodothyronine treatment in children after cardiac surgery: a double-blind, randomised, placebo controlled study. Lancet. 2000; 356: 529-534.

16. Hamilton MA, Stevenson LW, Fonarow GC. Safety and hemodynamic effects of intravenous triiodothyronine in advanced congestive heart failure. Am J Cardiol. 1998; 81: 443-447.

17. Malik FS, Mehra MR, Uber PA, et al. Intravenous thyroid hormone supplementation in heart failure with cardiogenic shock. J Card Fail. 1999; 5: 31-37.

18. Spooner PH, Morkin E, Goldman S. Thyroid hormone and thyroid hormone analogues in the treatment of heart failure. Coron Artery Dis. 1999; 10: 395-399.

19. Kozdag G, Ural D, Vural A, Agacdiken A, Kahraman G, Sahin T, Ural E, Komsuoglu B. Relation between free triiodothyronine/free thyroxine ratio, echocardiographic parameters and mortality in dilated cardiomyopathy. Eur J Heart Fail 2005; 7:113-118.

20. Iervasi G, Pingitore A, Landi P, Raciti M, Ripoli A, Scarlattini M, L’Abbate A, Donato L. Low-T3 syndrome: a strong prognostic predictor of death in patients with heart disease. Circulation 2003; 107:708-713.

\section{AUTHORS:}

1. Arun Kumar N.

2. S. M. Manjunatha

3. Yatish S. K.

4. Mohan Kumar

5. Ravi Shankar A. G.

6. Ramesh S. S.

7. M.M. Basavaraju

8. Shekar M. A.

\section{PARTICULARS OF CONTRIBUTORS:}

1. Senior Resident, Department of Medicine, ESIC, Bangalore.

2. Junior Resident, Department of Anaesthesia, NSMC, Kolkata.

3. Senior Resident, Departmetn of Anaesthesia, ESIC, Bangalore.

4. Consultant, Department of Medicine, Vatsalya Hospital, Mandya.

5. Professor, Department of Medicine, MMC \& RI, Mysore.
6. Assistant Professor, Department of Medicine, MMC \& RI, Mysore.

7. Assistant professor, Department of Medicine, MMC \& RI, Mysore.

8. Professor, Department of Medicine, MMC \& RI, Mysore.

\section{NAME ADDRESS EMAIL ID OF THE CORRESPONDING AUTHOR:}

Dr. Arun Kumar N,

B-192, $10^{\text {th }}$ Block, C.P.W.D. Quarters,

Bangalore - 560071.

E-mail: dreamfullofcream@gmail.com

Date of Submission: 23/01/2014.

Date of Peer Review: 24/01/2014.

Date of Acceptance: 08/02/2014.

Date of Publishing: 21/02/2014. 